\title{
Raman lidar profiling of water vapor and aerosols over the Southern Great Plains
}

\author{
Richard A. Ferrare \\ NASA Langley Research Center, Hampton, Virginia, 2368I, USA \\ r.ferrare@larc.nasa.gov \\ David D. Turner \\ Pacific Northwest National Laboratory, MS K9-38, Richland, Washington, 99352, USA \\ Lorraine A. Heilman \\ Science Applications International Corporation, Hampton, Virginia 23681, USA \\ Tim P. Tooman, John E. M. Goldsmith \\ Sandia National Laboratories, Livermore, California, 94551, USA \\ Oleg Dubovik \\ Science Systems Applications Incorporated, NASA GSFC, Greenbelt, Maryland 20771, USA \\ John A. Ogren \\ NOAA Climate Monitoring and Diagnostics Laboratory, Boulder, Colorado 80303, USA
}

\begin{abstract}
Raman lidar profiles of aerosol extinction and water vapor are used to characterize the vertical variability of aerosols and water vapor over northem Oklahoma. OCIS codes: (010.3640) Lidar; (010.3920) Meteorology
\end{abstract}

\section{Introduction}

The U.S. Department of Energy Atmospheric Radiation Measurement (ARM) program has developed and maintained an operational Raman lidar at its Southern Great Plains (SGP) Cloud and Radiation Testbed (CART) site in north-central Oklahoma ( $36.61 \mathrm{~N}, 97.49 \mathrm{~W})$. The CART Raman Lidar (CARL) was specifically designed to continuously measure profiles of water vapor and aerosols throughout the diumal cycle [1]. We have developed and implemented automated algorithms which use the Raman lidar data to retrieve profiles of water vapor mixing ratio, relative humidity, aerosol extinction and aerosol backscatter coefficients, linear depolarization ratio, and a cloud mask. Additional integrated products, such as total precipitable water vapor and aerosol optical thickness, are also routinely computed. We discuss the lidar system, the methodology for deriving water vapor and aerosol profiles, and how these profiles have been used to characterize the clear sky above the SGP site.

\section{Raman Lidar System}

CARL uses a tripled Nd:YAG laser, operating at $30 \mathrm{~Hz}$ with $350-400$ millijoule pulses to transmit light at $355 \mathrm{~nm}$. A $61-\mathrm{cm}$ diameter telescope collects the light backscattered by molecules and aerosols at the laser wavelength and the Raman scattered light from water vapor $(408 \mathrm{~nm})$ and nitrogen $(387 \mathrm{~nm})$ molecules. A beam expander reduces the laser beam divergence to $0.1 \mathrm{mrad}$, thereby permitting the use of a narrow $(0.3 \mathrm{mrad})$ as well as a wide (2 mrad) field of view. The narrow field of view, coupled with the use of narrowband ( $-0.4 \mathrm{~nm}$ bandpass) filters, reduces the background skylight and, therefore, increases the maximum range of the aerosol and water vapor profiles measured during daytime operations. The signals from the Rayleigh/Mie $(355 \mathrm{~nm})$, Raman $\mathrm{N}_{2}(387 \mathrm{~nm})$, and $\mathrm{Raman}_{2} \mathrm{O}$ $(408 \mathrm{~nm})$ channels are detected by photomultiplier tubes and recorded using photon counting with a vertical resolution of 39 meters. In normal operation, data are recorded as I-min profiles corresponding to the accumulation of signals from approximately 1780 laser shots. During post-processing, the vertical and/or temporal resolutions can be degraded to improve the signal/noise ratio.

Water vapor mixing ratio profiles are computed using the ratio of the Raman water vapor signal to the Raman nitrogen signal. These water vapor profiles are integrated with altitude to derive precipitable water vapor (PWV). The CARL water vapor mixing ratio profiles and PWV retrievals are automatically calibrated using the coincident nighttime measurements of precipitable water vapor (PWV) from the microwave radiometer (MWR) [2]. Relative humidity profiles are computed using water vapor mixing ratio profiles from CARL and temperature profiles 
derived using a physical retrieval from the high resolution downwelling longwave radiance data observed by the Atmospheric Emitted Radiance Interferometer (AERI) [3]. When averaged into 10-minute profiles, the lidar water vapor profiles are usually limited by the solar background to altitudes below approximately $3-4 \mathrm{~km}$ during the daytime, but typically extend to $10-12 \mathrm{~km}$ at night.

Profiles of aerosol scattering ratio, which is the ratio of aerosol+molecular scattering to molecular scattering, are derived using the Raman nitrogen signal and the signal detected at the laser wavelength. This profile is automatically calibrated by normalizing it to unity in a clear-air (cloud and aerosol free region) between $6-9 \mathrm{~km}$. Aerosol volume backscattering cross section profiles are then computed using the aerosol scattering ratio and molecular scattering cross section profiles derived from AERI retrievals of atmospheric density. For altitudes above $800 \mathrm{~m}$ where the overlap function for the nitrogen channel is unity, aerosol extinction coefficient profiles are computed from the derivative of the logarithm of the Raman nitrogen signal with respect to range. For altitudes below $800 \mathrm{~m}$, acrosol extinction profiles are derived from the aerosol extinction/backscatter ratio data from 800$1000 \mathrm{~m}$ together with the backscatter profile, which extends to $60 \mathrm{~m}$ above the surface. Aerosol optical thickness values are then computed by integrating the extinction coefficient profile from the surface to $7 \mathrm{~km}$ (or cloud base, whichever is lower).

\section{CARL Measurements}

Figure la shows average aerosol extinction profiles that were computed as a function of optical thickness to characterize the vertical distribution of aerosols. Figure $\mathrm{lb}$ shows water vapor mixing ratio profiles computed from the Raman lidar data. The scale height of the aerosol extinction profiles varies with both season and with AOT and shows more variability than does the scale height for water vapor mixing ratio.
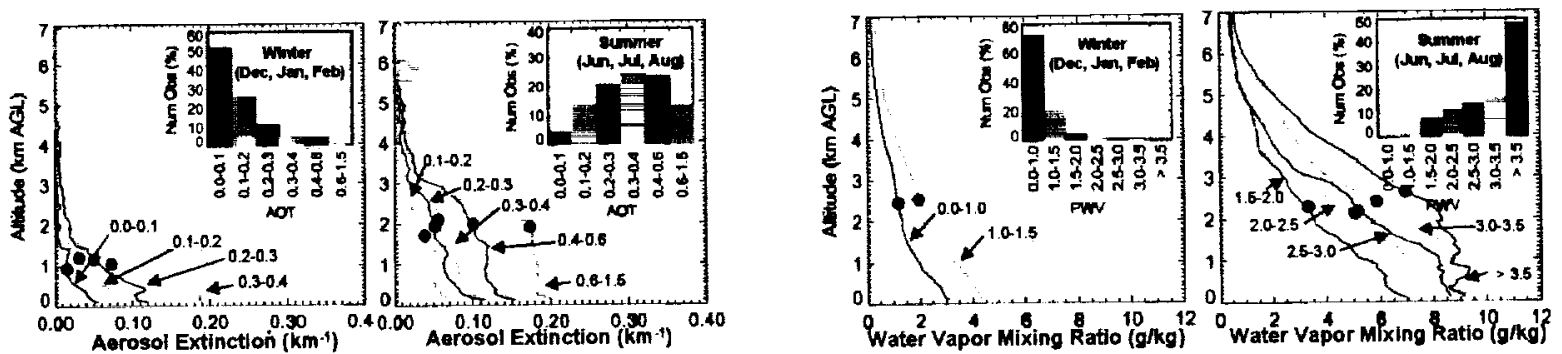

Figure la (left) Seasonal mean profiles, derived from data collected by the Raman lidar from April 1998 - January 2000, of aerosol extinction coefficient as a function of aerosol optical thickness (AOT). The inset plots indicate the fraction of the total number of samples for that season that was in the given bin. The range of AOT is indicated for each profile. Profiles were not plotted for bins with less than $5 \%$ of the total samples for the season. Black dots represent scale height (i.e. where distribution falls to $1 / \mathrm{e}$ of total integrated value.) $1 \mathrm{~b}$ (right) Same except for water vapor mixing ratio profiles as a function of precipitable water vapor (PWV).

Profiles of the aerosol extinction/backscattering ratio, $S_{a}$, were derived from the CARL data acquired during 1998 and 1999 . Mean values of $S_{a}$ at $355 \mathrm{~nm}$ typically ranged between 60 to 70 sr. Large $(>15 \%)$ variations in the vertical profile of $S_{a}$ occurred about $20 \%$ of the time, which implies that significant variability in the vertical distribution of the aerosol size distribution and/or composition often occurs. The Raman lidar measurements of $S_{a}$ were compared with estimates of particle size and refractive index derived from an algorithm that uses ground-based Sun photometer measurements of Sun and sky radiance [4]. Figure 2a shows that, during cases when $S_{a}$ did not vary greatly with altitude, the lidar and Sun photometer measurements of $S_{\mathrm{a}}$ showed good agreement.
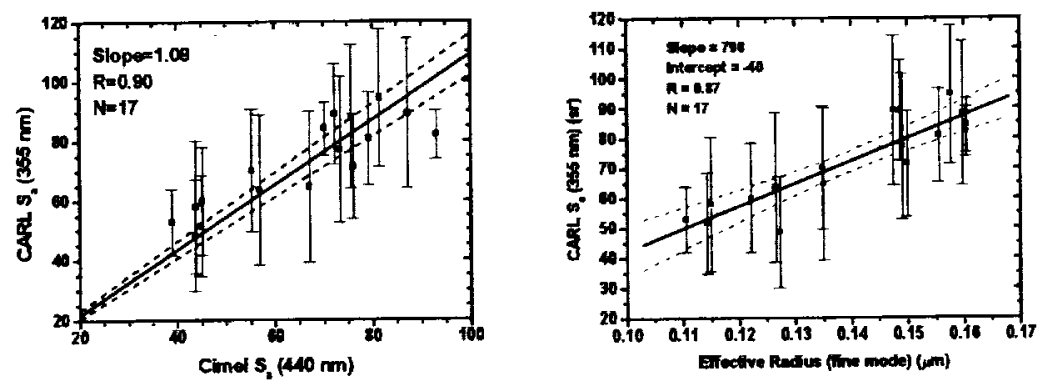

Figure $2 a$ (left) Comparison of $S_{a}$ derived from CARL data and retrieved from Sun and sky radiance inversion. $2 b$. (right) Correlation between $S_{2}$ and effective radius of the aerosol fine (accumulation) mode retricved from Sun and sky radiance inversion.

Optical Remote Sensing of the Atmosphere Topical Meeting, February 5-8, 2001, Coeur d'Alene, Idaho 
We have also begun comparing profiles of acrosol extinction and relative humidity derived from the CARL data with profiles derived from in situ sensors on a light aircraft flown periodically above the SGP site. These In-situ Aerosol Profiling (IAP) sensors include a nephelometer and particle soot/absorption photometer to measure dry (RH $<=40 \%$ ) aerosol scattering and absorption, respectively, and a Vaisala humicap hygrometer to measure relative humidity. Figure 3a shows a comparison of relative humidity and Figure $3 \mathrm{~b}$ shows a comparison of aerosol extinction. For the aerosol extinction comparison, the CARL profile at $355 \mathrm{~nm}$ was scaled to $550 \mathrm{~nm}$ using the aerosol scattering wavelength dependence measured by the nephelometer. The nephelometer aerosol scattering and extinction profiles were scaled to the ambient relative humidity using a humidification (i.e. hygroscopic growth) factor derived from measurements of light scattering as a function of relative humidity made at the surface. Both the lidar measurements of $S_{a}$ and the aircraft measurements of aerosol scattering and absorption are being used to examine the vertical variability of aerosols above the SGP site.
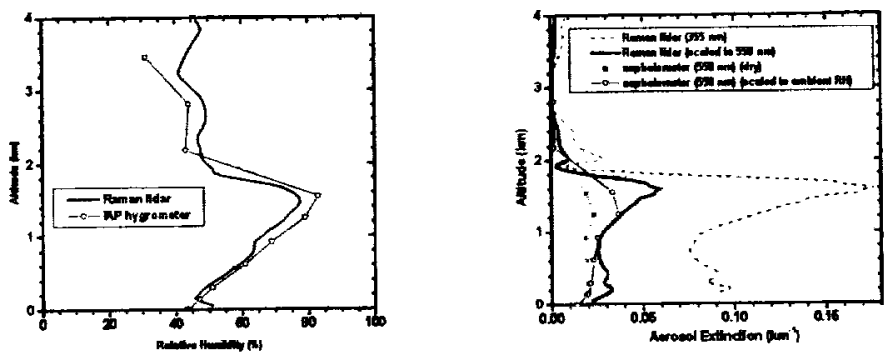

Fig. 3a) (left) Comparison of relative humidity derived from CARL data and measured in situ on IAP aircraft between 21:00-22:30 UT on May 4, 2000. 3b) (right) Comparison of aerosol extinction profiles derived from CARL and in situ aircraft data during this same period.

\section{Summary}

Profiles of water vapor mixing ratio, relative humidity, aerosol backscattering and extinction derived from CART Raman lidar data have been used to help study the vertical variability of water vapor and aerosols. These products have begun to demonstrate how this automated lidar system can be used to remotely characterize the clear sky over the ARM SGP site.

\section{Acknowledgements}

SGP CART Raman lidar, CIMEL Sun photometer, and AERI data were obtained from the Atmospheric Radiation Measurement (ARM) Program sponsored by the U.S. Department of Energy, Office of Energy Research, Office of Health and Environmental Research, Environmental Sciences Division. The CIMEL Sun photometer is also part of AERONET, a network of Sun photometers managed by B. N. Holben, NASA/GSFC. The IAP program is a joint effort between the ARM program and the NOAA Climate Monitoring and Diagnostics Laboratory. The DOE ARM and NASA EOS Validation Programs provided funding for this work. We thank Wayne Feltz for providing the temperature profiles retrieved from the AERI.

\section{References}

Goldsmith, J.E.M., F.H. Blair, S.E. Bisson, and D.D. Tumer: Tum-key Raman lidar for profiling atmospheric water vapor, clouds, and aerosols. Appl. Opt, 37, 4979-4990, (1998).

Turner, D.D., and J.E.M. Goldsmith: Twenty-Four hour Raman lidar measurements during the Atmospheric Radiation Measurement program's 1996 and 1997 water vapor intensive observation periods. J. Atmos. Oceanic Technol., 16, 1062-1076, (1999).

Feht, W.F., W.L. Smith, R.O. Knuteson, H.E. Revercomb, H.M. Woolf, and H.B. Howell, 1998: Meteorological applications of temperature and water vapor retrievals from the ground-based atmospheric emitted radiance interferometer (AER). J. Appl. Meteor., 37, 857-875, (1998).

Dubovik, O. A Smimov, B.N. Holben, M.D. King, Y.J. Kaufman, T.F. Eck, and I. Slutsker, Accuracy assessment of aerosol optical properties retrieved from AERONET Sun-and sky-radiance measurements, J. Geophys. Res., 105, 9791-9806, (2000). 